\title{
Within-Season Distribution of External Training and Racing Workload in Professional Male Road Cyclists
}

\author{
Alan J. Metcalfe, Paolo Menaspà, Vincent Villerius, Marc Quod, Jeremiah J. Peiffer, \\ Andrew D. Govus, and Chris R Abbiss
}

\begin{abstract}
Purpose: To describe the within-season external workloads of professional male road cyclists for optimal training prescription. Methods: Training and racing of 4 international competitive professional male cyclists (age $24 \pm 2 \mathrm{y}$, body mass $77.6 \pm$ $1.5 \mathrm{~kg}$ ) were monitored for 12 mo before the world team-time-trial championships. Three within-season phases leading up to the team-time-trial world championships on September 20,2015, were defined as phase 1 (Oct-Jan), phase 2 (Feb-May), and phase 3 (June-Sept). Distance and time were compared between training and racing days and over each of the various phases. Times spent in absolute $(<100,100-300,400-500,>500 \mathrm{~W})$ and relative $(0-1.9,2.0-4.9,5.0-7.9,>8 \mathrm{~W} / \mathrm{kg})$ power zones were also compared for the whole season and between phases 1-3. Results: Total distance (3859 $\pm 959 \mathrm{vs} 10911 \pm 620 \mathrm{~km})$ and time $(240.5 \pm 37.5$ vs $337.5 \pm 26 \mathrm{~h})$ were lower $(P<.01)$ in phase 1 than phase 2 . Total distance decreased $(P<.01)$ from phase 2 to phase $3(10911 \pm 620 \mathrm{vs} 8411 \pm 1399 \mathrm{~km}$, respectively). Mean absolute $(236 \pm 12.1$ vs $197 \pm 3 \mathrm{~W})$ and relative $(3.1 \pm 0$ vs $2.5 \pm 0 \mathrm{~W} / \mathrm{kg})$ power output were higher $(P<.05)$ during racing than training, respectively. Conclusion: Volume and intensity differed between training and racing over each of 3 distinct within-season phases.
\end{abstract}

Keywords: time trial, power output, SRM Powermeter, training load

Understanding the external workload demands of professional road cyclists is necessary to optimize training, reduce the risk of injury, and diagnose symptoms of overtraining. ${ }^{1}$ The use of power meters during professional cycling races and training allows for multiple external load measurements to be instantaneously collected during a ride. Athletes and sports scientists commonly analyze these measurements to assess performance and to aid in their decision-making processes.

The external workload in professional male cyclists has been previously described during road racing ${ }^{2-6}$ and training. ${ }^{7}$ While these studies add to a wealth of knowledge on external workload, the within-season distribution of workload during both training and racing is not well understood. Indeed, such research is limited to a detailed 50-week account of a world-class female triathlete in preparation for the Olympic-distance triathlon event. ${ }^{8}$ Therefore, the purpose of this study was to investigate the within-season distribution of external workload in 4 professional road cyclists throughout a cycling season and preparing for the world team-time-trial championships.

\section{Methods}

\section{Subjects}

The training and racing of 4 professional male cyclists (mean \pm SD age $24 \pm 2 \mathrm{y}$, body mass $77.6 \pm 1.5 \mathrm{~kg}$, height $184.0 \pm 4.3 \mathrm{~cm}$ ) from

Metcalfe, Menaspà, and Abbiss are with the Centre for Exercise \& Sports Science Research, Edith Cowan University, Joondalup, WA, Australia. Villerius is with the Cofidis Professional Cycling Team, France. Quod is with the Orica Greenedge Professional Cycling Team, Australia. Peiffer is with the School of Psychology and Exercise Science, Murdoch University, Murdoch, WA, Australia. Govus is with the Dept of Sport \& Physical Activity, University of Bedfordshire, Bedfordshire, UK. Address author correspondence to Alan Metcalfe at a.metcalfe@ecu.edu.au. the same professional cycling team were monitored for 12 months (October 2014 to September 2015) before the world team-time-trial championships held on September 20, 2015, in Richmond, VA, USA. The cyclists were classified as level 5 based on the study of De Pauw et al. ${ }^{9}$ Furthermore, all 4 cyclists had previously won a stage at the Giro D'Italia and 2 were winners of national ITT and road racing events. Body-mass measurements were taken in July and August 2015. All participants gave their written informed retrospective consent on the condition that individual data were reported as mean group data. The study was approved by the Edith Cowan University human ethics research committee.

\section{Experimental Design}

In total, 1124 training and racing files were retrospectively collated over the season with all participants competing in the team time trial at the championships. Fifty-six files were removed due to error, resulting in 1068 files retrospectively analyzed. For the purpose of this study, the cycling season was defined as October 2014 to September 2015. Within-season periodized macrocycles were defined by coaches/sports scientists as general base preparation (phase 1; October 14-January 15), racing (phase 2; February 15-May 15), and event-preparation (phase 3; June 15-September 15). All riders had planned to peak at similar times during the season and took part in a Giro D'Italia grand-tour cycling event in May 2015. The world team-time-trial championship was a flat (240-m elevation change $)^{10}$ $38.6-\mathrm{km}$ event with the winning team completing the course in 42 minutes 7 seconds $(55.2 \mathrm{~km} / \mathrm{h})$.

All training and racing data were collected using SRM (SRM Training Systems, Schoberer Rad Messtechnik, Jülich, Germany) power meters. All data were sampled at $1 \mathrm{~Hz}$. The SRM power meter device has been previously reported to have acceptable validity and reliability. ${ }^{11,12}$ All power meter were statically calibrated at the beginning of the season (November/December) and recalibrated if 
battery replacement occurred during the season. The SRM power control was set to automatically perform the zero-offset for every session (training and racing). After each training or racing session, race files were uploaded online with Training Peaks (Peaksware LLC, Lafayette, CO, USA) and later analyzed using Microsoft Excel.

\section{Data Analysis}

The total distance, time and mean absolute $(\mathrm{W})$ and relative $(\mathrm{W} / \mathrm{kg})$ power output were measured over the whole season and compared between phases 1 to 3 . Each phase consisted of 17 weeks. The total volume and mean absolute and relative power output were also separated into racing and training days and compared over the whole season. Furthermore, total volume and power output during training and racing for each week and in separate phases (1-3) were compared. Time spent within discrete, previously defined ${ }^{2,13}$ exerciseintensity power zones, in absolute $(<100,100-300,300-500$, and $>500 \mathrm{~W})$ and relative values $(0-1.9,2.0-4.9,5.0-7.9$, and $>8.0 \mathrm{~W} /$ $\mathrm{kg}$ ) were also evaluated between phases 1 to 3 .

\section{Statistical Analysis}

Linear mixed models were used to compare differences in mean total distance, time and mean power output overall, between training and racing days and the percentage of exercise intensity spent in each phase. Models were fitted using the "nlme" package (Version 3.1-127) ${ }^{14}$ and follow-up tests were conducted using the "phia" package in the R statistical program (R Core Development Team). All models were compared with a null model (ie, with no explanatory variables) using Akaike information criteria (AIC). Where necessary, models were fit with random intercept and slope to account for variable rates of change between each athlete and selected as the parsimonious model when minimizing the AIC value. Two-tailed statistical significance was accepted at $P \leq .05$. Results are expressed as mean $\pm \mathrm{SD}[95 \% \mathrm{CI}]$.

\section{Results}

The total distance, time and mean power output for the whole season and during phases 1 to 3 are summarized in Table 1 . Total distance increased from phase 1 to phase $2(40 \% ; P<.05)$.Furthermore, total distance decreased from phase 2 to phase $3(-22 \% ; P<.01)$. Absolute mean power output decreased from phase 2 to phase 3 $(-9 \% ; P<.01)$.
The comparison of total training and racing distance, time, and mean power output for the whole season and during phases 1 to 3 is summarized in Table 2. Training time was higher (39\%) than racing $(P<.05)$, and training absolute mean power output was lower $(19 \%)$ than racing $(P<.05)$. Racing distance increased by $192 \%$ from phase 1 to phase $2(P<.01)$. Racing time increased by $548 \%$ from phase 1 to phase $2(P<.01)$.

The percentage of time in each exercise intensity zone across each phase is displayed in Figure 1. Total time in the absolute 300- to $500-\mathrm{W}$ and relative 5.0- to $7.9-\mathrm{W} / \mathrm{kg}$ zone was higher in phase 2 than in phase $1(P<.01)$. Total time in the absolute 100 - to $300-\mathrm{W}$ and relative 2.0 - to $4.9-\mathrm{W} / \mathrm{kg}$ zone was lower in phase 2 than in phase $1(P<.01)$. Total time in the absolute $300-$ to $500-\mathrm{W}$ and relative 5.0 - to $7.9-\mathrm{W} / \mathrm{kg}$ zone was lower in phase 3 than in phase $2(P<$ $.05)$. Total time in the $100-$ to $300-\mathrm{W}$ and relative $2.0-$ to $4.9-\mathrm{W} / \mathrm{kg}$ zone was higher in phase 3 than in phase $2(P<.05)$.

The total weekly differences in training and racing duration and distance are displayed in Figure 2.

\section{Discussion}

The aim of this study was to investigate the within-season distribution of external workload in 4 professional male road cyclists racing throughout the cycling season and preparing for the world teamtime-trial championships. The distribution in total volume (distance and time) covered was significantly lower during phase 1 than phases 2 and 3 (Table 1). Furthermore, the total racing volume (distance and time) significantly increased from phase 1 to phase 2 (Table 2).

The off-season period for these specific professional road cyclists was during phase 1 , resulting in the observed lower total cycling distance covered, as well as lower total ride time (Table 1). While no differences were observed in relative mean power output between phases, a lower absolute mean power output during phase 3 compared with phases 1 and 2 (Table 1) was observed. It is plausible that during phase 1 , riders are completing longer aerobic-based training (279 training vs 30 race days) rides (Figure 2) compared with phase 3 (251 training vs 109 race days) however, lower absolute and relative mean power output intensities were not significantly different between phases (Figure 1). It is unsurprising that phase 2 resulted in the highest absolute mean power output due to all riders inclusion in a grand-tour event also resulting in the greatest amount of racing days during phase 2 (167 days). After the grand tour, riders conducted a lower-intensity recovery period, possibly causing the lower absolute mean power output in the final phase. Furthermore, in preparation for

\section{Table 1 Total Absolute and Relative Distance, Time, and Power Output for the Whole Season and During Each Periodized Phase, Mean \pm SD $[95 \% \mathrm{Cl}]$}

\begin{tabular}{|c|c|c|c|c|}
\hline & Whole season $(\mathrm{N}=1068)$ & Phase $1(n=309)$ & Phase 2 ( $n=399)$ & Phase $3(n=360)$ \\
\hline \multirow[t]{2}{*}{ Total distance $(\mathrm{km})$} & $26448 \pm 2765$ & $6859 \pm 959^{*}$ & $10911 \pm 620$ & $8411 \pm 1399 *$ \\
\hline & {$[22048,30849]$} & {$[5332,8386]$} & {$[9924,11898]$} & {$[6185,10638]$} \\
\hline \multirow[t]{2}{*}{ Total time (h) } & $856 \pm 80.3$ & $240.5 \pm 37.5^{*}$ & $337.8 \pm 26$ & $292.5 \pm 6.3$ \\
\hline & {$[728.9,984.6]$} & {$[180.7,300.3]$} & {$[295.4,380.1]$} & {$[235.3,349.7]$} \\
\hline \multirow[t]{2}{*}{ Absolute power output (W) } & $208 \pm 5$ & $216 \pm 9 * *$ & $221 \pm 8$ & $201 \pm 6^{*}$ \\
\hline & {$[199,218]$} & {$[201,231]$} & {$[208,234]$} & {$[191,211]$} \\
\hline \multirow[t]{2}{*}{ Relative power output (W/kg) } & $2.8 \pm 0.3$ & $2.8 \pm 0.3$ & $2.8 \pm 0.3$ & $2.6 \pm 0.3$ \\
\hline & {$[2.6,2.9]$} & {$[2.5,3.2]$} & {$[2.4,3.3]$} & {$[2.3,3]$} \\
\hline
\end{tabular}

*Significantly different $(P<.05)$ from phase $2 . * *$ Significantly different $(P<.05)$ from phase 3. 


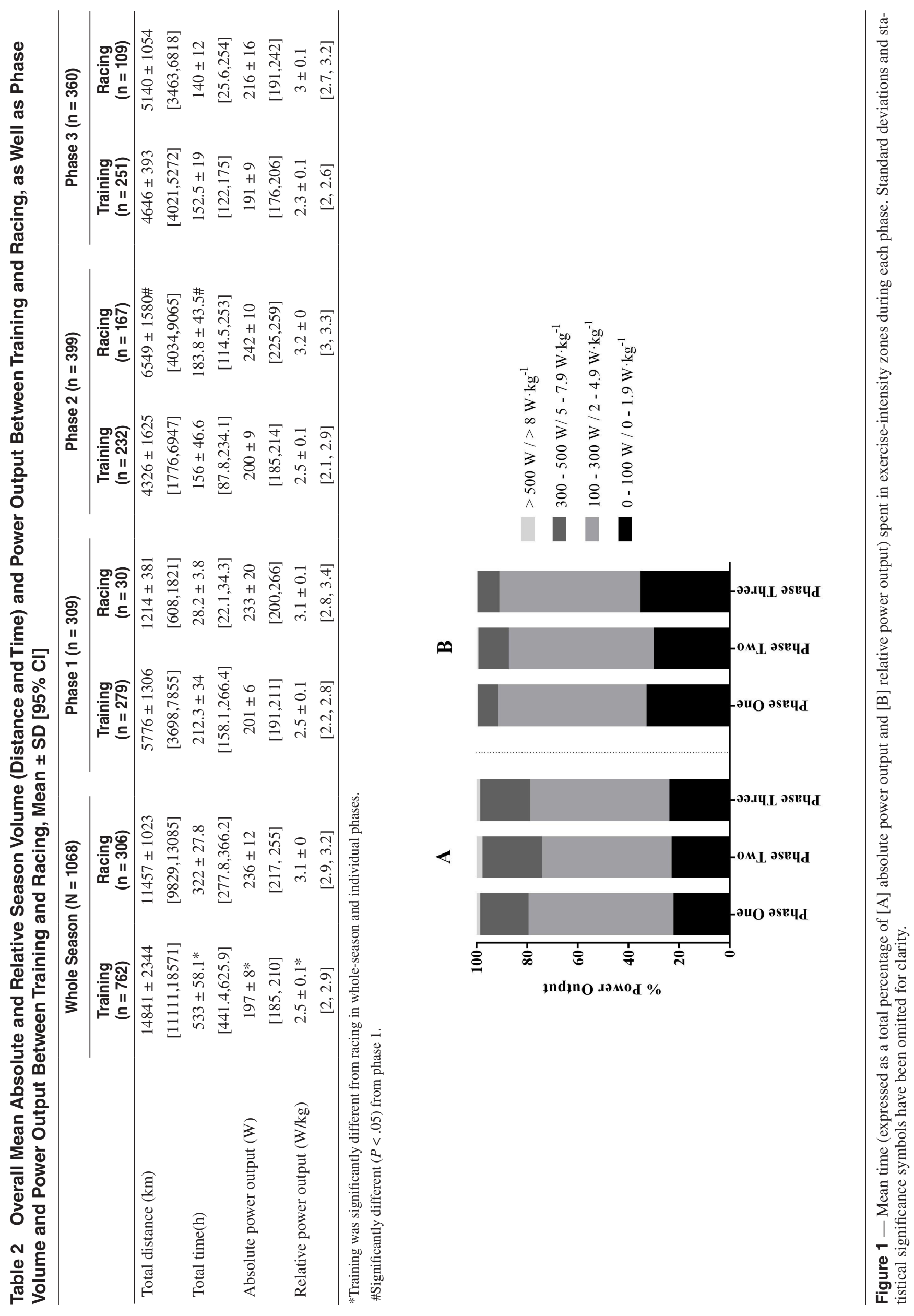




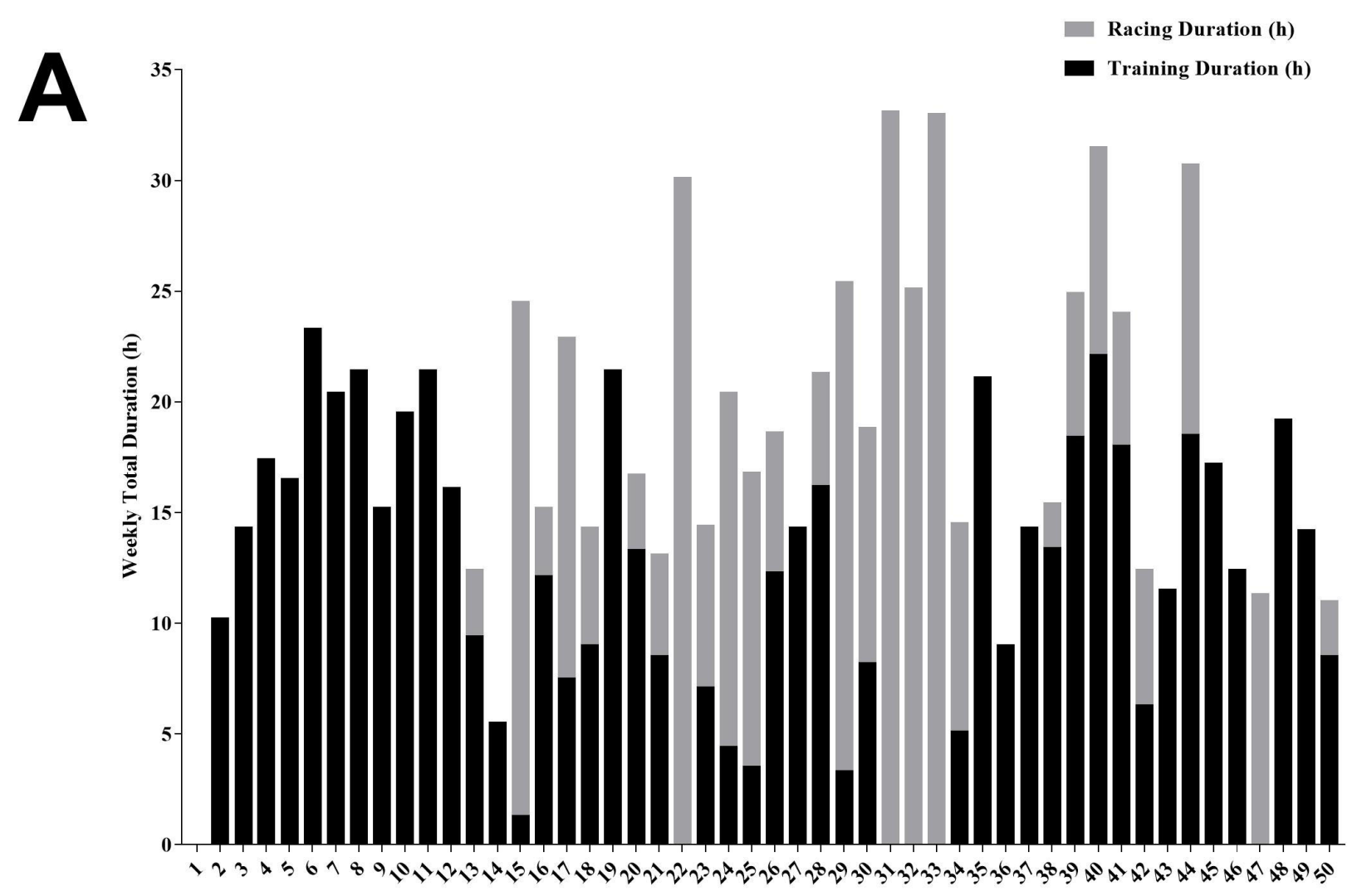

Weeks

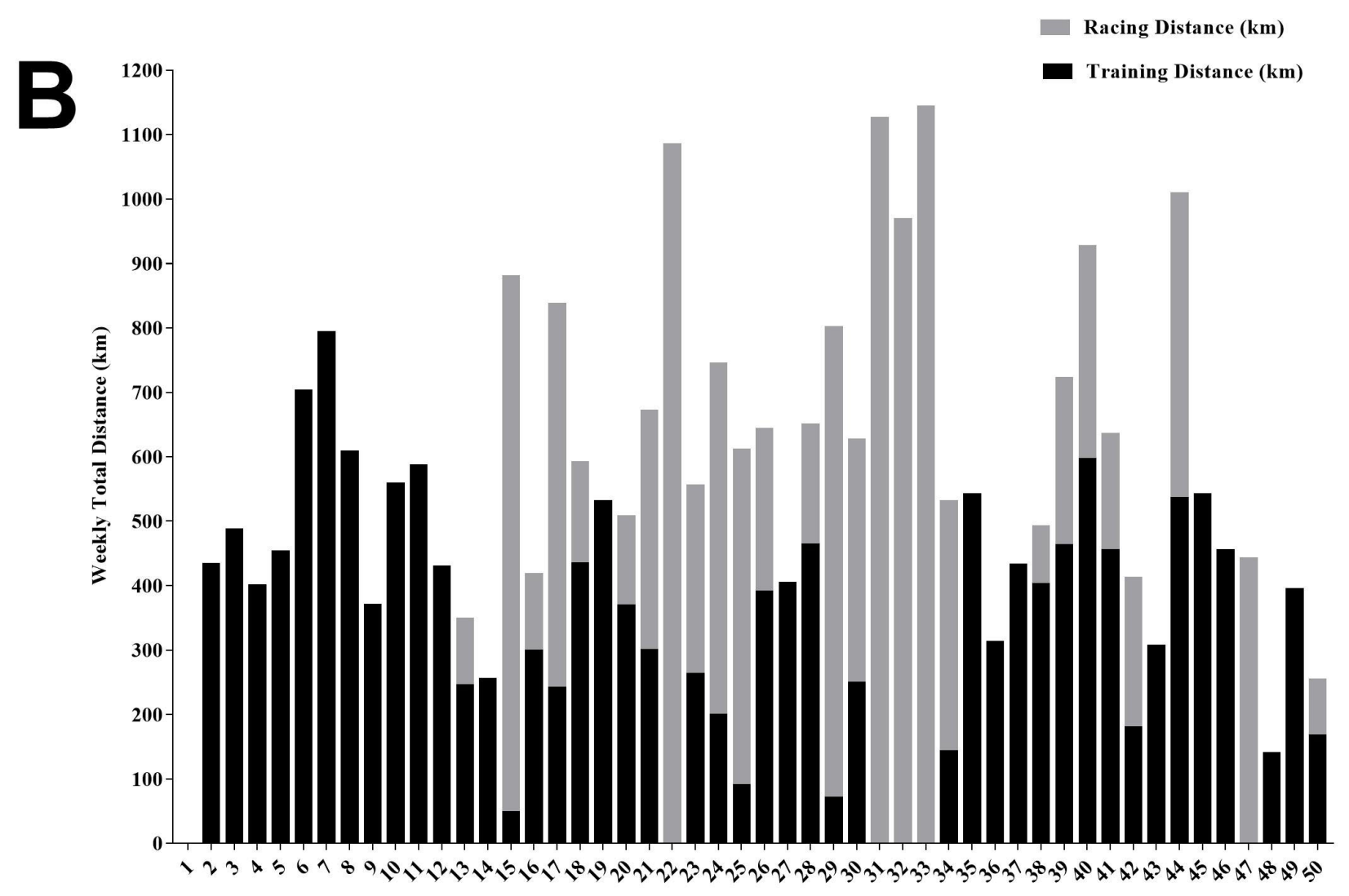

Weeks

Figure 2 - The mean weekly total (A) duration and (B) distance for training and racing over the whole season. 
the world team time trial championship, time was spent on time-trial bikes, which could cause an overall lower mean absolute power output.

Differences were observed in the time spent in absolute (100-300 and 300-500 W) and relative (2.0-4.9 and 5.0-7.9 W/kg) power-output intensity zones (Figure 1). Time in the 300- to 500-W zone significantly increased from phase $1(19 \%)$ to phase $2(23.4 \%)$. An increase by $4 \%$ was also seen in the relative $5.0-$ to $7.9-\mathrm{W} / \mathrm{kg}$ zone. This demonstrates that riders were spending more time at a lower intensity (100-300 W/2.0-4.9 W/kg) during the off-season in phase 1 (Table 2). Much of this increase in cycling intensity is likely to be the result of greater racing in phase 2 . Indeed, by examining the week-by-week variation in training distance and duration (Figure 2), participants considerably reduce training load to compensate for increased competition. Whether such training optimally prepares athletes for competition is not clear. However, results of the current study highlight the training and competition demands of elite-level cyclists. As a result of the increased time during phase 2 in the absolute 300 - to $500-\mathrm{W}$ zone, a lower percentage time in the 100 - to $300-\mathrm{W}$ zone in phase $2(51.2 \%)$ compared with phase 1 $(57.3 \%)$ was observed. This observation was also evident in relative power-output intensity zones. These results are similar to previously reported adjustments ${ }^{7}$ in the training intensity of elite under- 23 male road cyclists between winter and spring periods. Note that phase 3 showed the reverse effect with time in the absolute 300 - to $500-\mathrm{W}$ zone decreasing (19.6\%), resulting in an increase in time during the 100 - to $300-\mathrm{W}$ zone $(55 \%)$, similar to phase $1(57.3 \%)$. This observation is also supported by the relative power output with a $5.3 \%$ increase between phases 2 and 3 in the time spent at 0 to $1.9 \mathrm{~W} / \mathrm{kg}$. Although a decline in overall training and racing volume would be expected in tapering preparations ${ }^{15}$ for the world team time trial, a considerable reduction in the time spent at threshold (300-500 $\mathrm{W} / 5.0-7.9 \mathrm{~W} / \mathrm{kg}$ ) intensities was observed throughout phase 3 . The reduction in training volume at threshold throughout this phase, and not just in the taper for this event, could be due to riders spending a long period of time racing a grand tour event in phase 2 followed by short high-intensity races in phase 3 (Figure 2). A limitation of these observations in this study are that body mass was only measured at the beginning of the season (November/December). Variation in body mass during the season may have altered the measurement of relative power output and therefore influenced the interpretation of our data. Future research should regularly measure body mass throughout the season to obtain a more accurate determination of relative power output and provide individualized training zones.

In conclusion, this study describes the within-season distribution of external workload in 4 professional road cyclists. It was found that volume and intensity differed between training and racing over each of 3 distinct within-season phases. This investigation provides a brief insight into within-season training and racing differences in professional male road cyclists.

\section{References}

1. Borresen J, Lambert MI. The quantification of training load, the training response and the effect on performance. Sports Med. 2009;39(9):779795. PubMed doi:10.2165/11317780-000000000-00000
2. Ebert TR, Martin DT, Stephens B, Withers RT. Power output during a professional men's road-cycling tour. Int J Sports Physiol Perform. 2006;1(4):324-335. PubMed doi:10.1123/ijspp.1.4.324

3. Vogt S, Schumacher YO, Roecker K, et al. Power output during the Tour de France. Int J Sports Med. 2007;28(9):756-761. PubMed doi:10.1055/s-2007-964982

4. Vogt S, Schumacher YO, Blum A, et al. Cycling power output produced during flat and mountain stages during the Giro D'Italia: a case study. J Sports Sci. 2007;25(12):1299-1305. PubMed doi:10.1080/02640410601001632

5. Pinot J, Grappe F. A six-year monitoring case study of a top-10 cycling Grand Tour finisher. J Sports Sci. 2015;33(9):907-914. PubMed doi :10.1080/02640414.2014.969296

6. Pinot J, Grappe F. The record power profile to assess performance in elite cyclists. Int J Sports Med. 2011;32(11):839-844. PubMed doi:10.1055/s-0031-1279773

7. Zapico AG, Calderón FJ, Benito PJ, et al. Evolution of physiological and haematological parameters with training load in elite male road cyclists: a longitudinal study. J Sports Med Phys Fitness. 2007;47(2):191-196. PubMed

8. Mujika I. Olympic preparation of a world-class female triathlete. Int J Sports Physiol Perform. 2014;9(4):727-731. PubMed doi:10.1123/ ijspp.2013-0245

9. De Pauw K, Roelands B, Cheung SS, de Geus B, Rietjens G, Meeusen R. Guidelines to classify subject groups in sport-science research. Int J Sports Physiol Perform. 2013;8(2):111-122. PubMed doi:10.1123/ ijspp.8.2.111

10. Menaspà $P$, Impellizzeri FM, Haakonssen EC, Martin DT, Abbiss CR. Consistency of commercial devices for measuring elevation gain. Int J Sports Physiol Perform. 2014;9(5):884-886. PubMed doi:10.1123/ ijspp.2013-0232

11. Abbiss CR, Quod MJ, Levin G, Martin DT, Laursen PB. Accuracy of the Velotron ergometer and SRM power meter. Int J Sports Med. 2009;30(2):107-112. PubMed doi:10.1055/s-0028-1103285

12. Gardner AS, Stephens S, Martin DT, Lawton E, Lee H, Jenkins D. Accuracy of SRM and power tap monitoring systems for bicycling. Med Sci Sports Exerc. 2004;36(7):1252-1258. PubMed doi:10.1249/01.MSS.0000132380.21785.03

13. Ebert TR, Martin DT, McDonald W, Victor J, Plummer J, Withers RT. Power output during women's world cup road cycle racing. Eur J Appl Physiol. 2005;95(5-6):529-536. PubMed doi:10.1007/ s00421-005-0039-y

14. Pinheiro J, Bates D, DebRoy S, Sarkar D. R core development team. nlme: linear and nonlinear mixed effects models. $R$ package. 2013;3:57.

15. Bosquet L, Montpetit J, Arvisais D, Mujika I. Effects of tapering on performance: a meta-analysis. Med Sci Sports Exerc. 2007;39(8):1358-1365. PubMed doi:10.1249/mss.0b013e31806010e0 